\title{
CAROLYN P. BOYD
}

\author{
JOSÉ ÁLVAREZ JUNCO \\ Universidad Complutense de Madrid \\ jajunco@gmail.com
}

Cómo citar/Citation

Álvarez Junco, J. (2017).

Carolyn P. Boyd

Historia y Política, 37, 389-394.

doi: https://doi.org/10.18042/hp.37.14

Carolyn Boyd, catedrática de Historia de España en la Universidad de California y miembro destacado de la Association for Spanish and Portuguese Historical Studies, falleció en el verano de 2015. No creo que sea exagerado decir que, en el momento de su muerte, era la hispanista senior más activa y de máximo prestigio en los Estados Unidos.

A lo largo de los últimos cuarenta años, su tarea como historiadora se desplegó, al menos, en tres campos. En primer lugar, militarismo y vida política española de los siglos XIX y XX, objeto del libro publicado por la University of North Carolina en 1979 bajo el título Praetorian politics in liberal Spain (trad. cast. La política pretoriana en el reinado de Alfonso XIII, Alianza Editorial, 1990). En segundo, la construcción de la identidad nacional, vista a través de la política educativa y los libros escolares, tema de su Historia patria: Politics, history, and national identity in Spain, 1875-1975, publicada por Princeton University Press en 1997 (en cast. Historia patria: política, historia e identidad nacional en España: 1875-1975, Pomares-Corredor, 2000). Como tercer y último polo de interés, el nacionalismo, de nuevo, pero esta vez en relación con el catolicismo, y encarnó en su Religión y política en la España contemporánea, obra que coordinó y a la que contribuyó con un prólogo y un largo artículo, publicada en 2007 por el Centro de Estudios Políticos y Constitucionales. 
El origen de su primer libro fue su tesis doctoral, dirigida por Joan C. Ullman, la inolvidable especialista en la Semana Trágica. Partió de una investigación realizada en los años setenta, cuando el acceso a los archivos militares era aún difícil, aunque menos para ella, joven extranjera de apariencia inocua. Lo que escribió, sin embargo, fue un análisis nada complaciente de la interferencia militar en la vida política española que acabó desembocando en las dos dictaduras del Xx.

Aunque Boyd centraba su indagación en el período comprendido entre la débacle de 1898 y el golpe de Primo en 1923, dedicaba largas páginas iniciales a describir la organización y los problemas heredados del siglo anterior. Fundamentada en trabajos previos, como los de Eric Christiansen o Stanley Payne, y en teóricos sobre el pretorianismo como Amos Perlmutter o Samuel Huntington, analizaba el número de oficiales, el sistema de ascenso, la composición social de los reclutas, las rivalidades corporativas o los recursos presupuestarios a disposición del Ejército. Sobre el primero de estos problemas, baste recordar que en España había un oficial por cada cinco soldados, mientras que en Francia o Alemania había uno por cada veinte. En cuanto a los reclutas, las clases altas evadían el servicio militar de sus hijos incluso tras la ley Canalejas de 1912. Las rivalidades corporativas imposibilitaron el establecimiento de una única academia militar (la creada por Martínez Campos en 1882 fue eliminada en 1892 por López Domínguez, artillero y contrario a formación uniforme). Todos estos problemas tenían relación con la identificación del rey con los militares frente a los políticos y con el anclaje que el propio Cánovas hizo del régimen y del orden social en el Ejército. La Constitución no ofrecía a los militares una amplia representación en las Cortes, pero sus intereses estaban salvaguardados por políticos civiles o por la propia Corona. Encastillados en sus privilegios, los generales consideraban cosa propia el gobierno interno del ejército.

Boyd ponía así en cuestión la idea, tan repetida, de que Cánovas había eliminado el intervencionismo militar en la vida política. El Ejército no se pronunciaba ya para alternar a los partidos en el poder, como había hecho en los dos primeros tercios del siglo, pero era el garante corporativo de la monarquía y del régimen parlamentario oligárquico tanto contra los movimientos obreros como contra los nacionalismos periféricos. De ahí que en el siglo Xx, al revés que en el XIX, el Ejército interviniera como institución, siempre en nombre del orden público y la unidad de la patria. El gran ejemplo fue el asunto del Cu-Cut! de 1905-1906, que dio origen a la Ley de Jurisdicciones. El Gobierno toleró entonces la indisciplina militar, socavó la libertad constitucional de expresión y ofendió a los catalanistas; todo antes que enfrentarse con el conjunto del Ejército. Es revelador comparar esta ley con el affaire 
Dreyfus francés, otro pulso entre la prensa y los tribunales militares de resultados diametralmente opuestos.

El sistema demostró ser irreformable. Frente a los intentos del general Luque en 1916-1917 se alzó el corporativismo de las Juntas de Defensa, que hizo caer al ministro. Y esta imposibilidad de reforma era importante, porque para Boyd la profesionalización del Ejército era un aspecto crucial de la modernización y democratización del sistema político en su conjunto.

No muy diferente era la llamada "cuestión social». Al enfocarla en términos de orden público, los Gobiernos convirtieron al Ejército en la columna vertebral del orden jerárquico heredado, el «invencible dique contra los intentos ilegales del proletariado», según lo describió Cánovas. Muchos militares creían, sinceramente, no estar al servicio de intereses de clase; no se identificaban con la oligarquía e incluso simpatizaban con las reivindicaciones obreras. Pero lo incuestionable era el orden, la unidad de la patria, la jerarquía social; y detestaban los aspectos internacionalistas y antimilitaristas del obrerismo español. En las situaciones que amenazaban con graves desórdenes, los Gobiernos recurrían sistemáticamente al ejército. Y la represión, sin los medios policiales adecuados, llevaba a consecuencias sangrientas.

La espoleta que hizo estallar este explosivo conjunto fue la guerra marroquí. Arrastrados por la coyuntura internacional, los gobernantes españoles se lanzaron a aquella empresa sin entusiasmo ni apoyo por parte de la opinión. Y el Ejército demostró su ineficacia operativa. Lo cual añadió un motivo más de descontento a los problemas heredados. Y como las responsabilidades alcanzaban al propio rey, la situación acabó llevando al golpe de Primo de Rivera.

La segunda gran obra de nuestra autora fue Historia patria, un libro a caballo entre la historia de la educación y la del nacionalismo. Fue un estudio de la evolución del sistema educativo entre la ley Moyano de 1857 y la dictadura de Primo de Rivera en 1923, centrándose especialmente en los manuales escolares de historia de España. En estos encontraba que había diversas versiones, especialmente la liberal y la nacionalcatólica, rivales y conflictivas en muchos aspectos. Pero llegaba mucho más lejos: explicaba los bajos niveles de compromiso cívico, la llamativa ausencia de un movimiento nacionalista de masas, el débil atractivo que suscitaba la identidad nacional y el desinterés de los padres por el tipo de enseñanza que sus hijos recibían (no así por el coste de los libros de texto o por el título que ganaban con sus estudios). Los Gobiernos, en definitiva, no se esforzaron seriamente por nacionalizar a las masas. En un mundo mental prenacional, las élites dirigentes creían prioritario inculcar el sentimiento religioso para mantener el orden social. Al revés que los gobernantes franceses o alemanes, y a pesar de que Cánovas, su gran 
mentor, era historiador y profundamente nacionalista, los conservadores españoles no promocionaron la historia en la escuela. Los liberales, en cambio, más modernos, escribieron historias nacionales e incluso pergeñaron un mito sobre el pasado que legitimaba sus propuestas políticas.

Esta segunda obra de Carolyn Boyd se vio complementada por el largo capítulo que escribió para Las historias de España. Visiones del pasado y construcción de identidad, que yo mismo coordiné en 2011 (Barcelona, Crítica, y Madrid, Pons). Se extendió allí sobre la oferta de «nacionalismo cívico» de la Segunda República, el nacionalcatolicismo franquista y las polémicas sobre la enseñanza de la historia en la España democrática. A lo largo de estos trabajos, su principal asunción fue siempre la centralidad de la enseñanza de la historia para la construcción nacional. La nación se construía, básicamente, en la escuela. Pero pronto extendería su interés al campo, más amplio, de la política cultural (monumentos, conmemoraciones). Fue cuando comenzó a trabajar sobre religión y política.

Pese a la importancia del catolicismo y la Iglesia en el pasado español, la historia de la religión en España sigue siendo hoy un terreno mal cultivado, en comparación con otros países. Durante mucho tiempo, se ha limitado a la historia eclesiástica, aunque recientemente, y gracias al auge de la historia cultural, han aparecido estudios de mucha mayor calidad, como los de Frances Lannon, William Callahan o el propio Stanley Payne. No sabemos aún, sin embargo, cómo vivieron la religión los individuos corrientes. Para investigarlo, Boyd organizó seminarios en California y Madrid, en 2002-2003, bajo el patrocinio de la Fundación Del Amo, y finalmente un coloquio internacional que tuvo lugar en el Centro de Estudios Políticos y Constitucionales en octubre de 2005. El resultado fue un volumen coordinado por ella y publicado por este mismo Centro.

Boyd explica la idea central del libro en la introducción. La transición a la democracia liberal moderna se vio acompañada en Europa por un proceso de secularización. Política, derecho, economía, educación, se emanciparon de la influencia de la religión y de la autoridad de las iglesias. En el caso español, la institución eclesiástica, al oponerse a la libertad de conciencia, al pluralismo ideológico y a la apertura del sistema político a la participación popular, se erigió en valla de contención frente a los valores cívicos de la modernidad. Pero el proyecto político absolutista, apoyado por la mayoría del clero católico, fue derrotado militarmente y la Iglesia debió optar entre negarse a reconocer la legitimidad del nuevo orden político liberal-parlamentario o salvaguardar sus intereses, en la medida de lo posible, dentro del mismo. Hacia 1900, la mayoría del clero había optado ya por la segunda opción, reconociendo la emancipación de la esfera política pero luchando por mantener, dentro de la sociedad 
liberal, ritos y prácticas religiosas tradicionales que preservaban la identidad católica. La Iglesia de la Restauración consiguió grandes privilegios a cambio de no oponerse frontalmente al sistema parlamentario liberal. Todo ello con poco entusiasmo y dominada siempre por temores a la secularización y el anticlericalismo.

La crisis política y cultural de comienzos del siglo xx creó un ambiente de inseguridad y afán de redención colectiva que generó regímenes totalitarios y politizó a las religiones tradicionales de nuevas maneras. Unas ideologías políticas radicalizadas proclamaron ser poseedoras de la verdad, lo que generó verdaderas «religiones civiles» en las democracias y «religiones políticas» en los totalitarismos. La política de la era de masas se sacralizó, con fenómenos de imitación, adaptación y rivalidad con las religiones heredadas y pugnas entre dirigentes políticos y religiosos para fortalecer sus posiciones aprovechando los recursos del otro. Al colaborar las religiones en la legitimación simbólica del orden político y social, se reforzó la unión de los ciudadanos en "comunidades imaginadas» que eran naciones sacralizadas.

En España, la Iglesia prestó su autoridad espiritual a los rebeldes de 1936, confirió legitimidad al franquismo, rivalizó luego con -y derrotó alos falangistas y se embarcó en una misión de recristianización de la sociedad española. Valores conservadores autoritarios típicamente católicos, como el paternalismo, el patriarcado o la obediencia y el respeto hacia relaciones de género y jerarquías sociales establecidas, coincidían con la visión dictatorial de la ciudadanía, el orden social y la estructura política. Pero en el último franquismo, y ante la imparable secularización, surgieron en el clero voces críticas contra la unión de la Iglesia con un régimen represivo. Durante la Transición, la Iglesia aceptó su separación formal del Estado.

Aspectos de especial interés para Boyd son el papel de la Iglesia y la religión en la construcción de las identidades cívicas, la movilización de los grupos sociales y la configuración de la esfera pública en la España del xx. En este volumen dirigido por ella, diversos autores estudian el papel de las costumbres y los discursos cotidianos en la formación de culturas políticas e identidades grupales, la competición entre la Iglesia y los anticlericales por un mismo espacio público y universo simbólico y la configuración de la identidad femenina (con el contradictorio papel preponderante de las mujeres en movimientos católicos conservadores mientras que se veían excluidas de la vida pública por parte de la izquierda anticlerical, lo que hizo que fueran las mujeres católicas las que protagonizaron la nueva concepción de la ciudadanía femenina en la esfera pública).

El volumen se cierra con las dimensiones religiosas que tienen las políticas de la memoria y la identidad en la España moderna. Es decir, el importante 
papel de la Iglesia como agente de nacionalización, a través de políticas de la memoria que crearon o reforzaron identidades nacionales y regionales. Se estudian las cartas y sermones pastorales sobre la historia nacional y el equívoco que suponía este reforzamiento de la nación por parte de alguien que no quería fortalecer al Estado. Y la propia Carolyn Boyd estudia el mito de Covadonga, su evolución y su apropiación final por la Iglesia como espacio sagrado en el que se unen la nación y la fe.

Los significados de Covadonga en la mitología española eran, en principio, variados: podía verse, por ejemplo, como una intervención divina que había asegurado la victoria cristiana el 718 o como lugar de representación del primer drama de la épica nacional. El santuario se convirtió, así, en campo de competición entre Iglesia y Estado, entre conservadores y liberales o entre región y nación. Todos querían apropiarse de él y controlar su significado simbólico. Así había ocurrido desde sus orígenes medievales, pero se reactivó en el siglo XIX, cuando — ante el éxito de Lourdes— se reconstruyó el santuario gracias a Pidal, asturiano titular de Fomento en 1884 y pilar del regionalismo conservador católico. Hubo también un grupo intelectual republicano, vinculado a la Universidad de Oviedo, que comprendió el potencial del mito y quiso hacer de la figura de Don Pelayo un símbolo de libertad, patriotismo e independencia nacional. Bajo Alfonso XIII se inició el lanzamiento turístico del lugar, con tranvía, carreteras, hostal y funicular. Pero, al celebrarse en 1918 el duodécimo centenario de la batalla, la inactividad del Gobierno contrastó con la coronación canónica de la Virgen de Covadonga por parte del papa. El Siglo Futuro resumió la situación: «Es nuestro centenario». En efecto, la Iglesia se había apropiado de Covadonga, como se demostró durante la Segunda República, cuando fue sede de mítines tradicionalistas y de la CEDA mientras las élites industriales e intelectuales modernizadoras, aceptando su derrota, se centraban en la Asturias minera. Despojada de su complejidad, Covadonga fue arma de la derecha en el conflicto ideológico partidista.

Otras muchas cosas hubiera hecho Carolyn Boyd de haber tenido tiempo para ello, porque siguió trabajando hasta el último día. Fue, además de una gran historiadora, una persona entrañable y modesta. Su muerte se añade a las de Christopher Schmidt-Nowara o Edward Malefakis, ocurridas también en los últimos doce meses. En años anteriores han fallecido Joan Ullman o los británicos Raymond Carr o Ronald Fraser. Y se han retirado Gabriel Jackson, Stanley Payne o Richard Herr. Desaparece aquella gran generación de hispanistas a la que cabe el mérito de haber arrebatado los estudios sobre historia de España del fantasioso mundo del estereotipo romántico. Boyd, algo más joven que ellos, consolidó y expandió su senda con una fuerza y una inteligencia excepcionales. Todos debemos agradecérselo. 